IOSR Journal of Pharmacy

e-ISSN: 2250-3013, p-ISSN: 2319-4219, www.iosrphr.org

Volume 2 Issue 6 ||| Nov-Dec. 2012 || | PP.52-59

\title{
A Retrospective Study of Acute Promyelocytic Leukemia
}

\author{
${ }^{1}$ Mashood Ahmed Shah, ${ }^{2}$ Ashish Gupta, \\ ${ }^{3}$ Sandeep Kaur, ${ }^{4}$ Mohd.Gousuddin \\ ${ }^{I}$ Master of Science in Medical laboratory technology (Lecturer) \\ ${ }^{2}$ M.B.B.S, M.D (Pathologist), ${ }^{3}$ BMLT, (Student), ${ }^{4}$ Master of Pharmacy (Lecturer) \\ Siddhartha institute of paramedical science, dehradun1 Dr.lal path labs, new delhi2 \\ Lincoln university college malaysia3
}

\begin{abstract}
Objective:-To study the incidence of acute promyelocytic leukemia (APL) in the department of Haematology Dr Lal path Labs, New Delhi from year 2002 to December 2008 in relation to age, sex, morphology, molecular and cytogenetic (HLA-DR) analysis.

To demonstrate various morphological types of Acute promyelocytic Leukaemia (APL)

To estimate the percentage of APL of the total acute leukemia.

Methods:-The present retrospective study was carried out to ascertain the incidence of acute promyelocytic Leukemia (FAB-M3) diagnosed at Dr Lal path Labs, New Delhi from year 2002 to December 2008.All relevant data including clinical record concerning age, sex, laboratory finding, cytochemistry, cytogenetic, haematological parameter and history of bleeding were retrieved from the laboratory records departments of the Laboratory. In all cases bone marrow slides were examined and whenever necessary they were restained. Results:-A total of 206 patients were diagnosed as acute leukemia. Out of which 94 cases were acute myeloid leukemia and rest of them (112) were Acute Lymphocytic Leukemia (ALL). Out of AML, 26 cases were conformed as APL.Thus the incidence of APL among total cases of acute leukemia was 12.6\% and APL constituted $27.6 \%$ of total AML cases.

Conclusion:-There are Very few studies available in Indian literature on the relative incidence of APL in Indian population, the data in literatures were analyzed and compared with observation of present study. The Result of the study was compared with the observations of other study available on the subject and after comparative review of available literature the following conclusion was drawn:

1. The incidence of APL (26\%) was found to be higher at our centre of study in comparison to other studies. So there is a need for multicentric studies having a large population based to know actual incidence rate in our country.

2. Males were found to be affected more comprising $76.9 \%$ of the cases giving a male and female ratio (M: F) of 3.3:1

3. The main age incidence of APL in our study was 40 years. The majority of the patient was the age group between 20 to 40 years but few patients were found above 60 years of age.

Keywords
$A M L$
: Acute Myeloid Leukemia.
$A L L$
: Acute Lymphocytic Leukemia
$A P L$
: Acute Promyelocytic Leukemia
$H L A-D R$
$F A B$
: Human leukocyte Antigen - DR
: French American British
$P M L-R A R \alpha$
: Promyelocytic Leukemia- Retinoic acid receptor alpha.

\section{INTRODUCTION}

Acute myeloid leukemia (AML) is referred to a group of marrow based neoplasm that have clinical similarities but distinct morphologic, Immunophenotypic and cytogenetic features. The FAB classification identifies eight sub types of AML; four types (M0, M1, M2, and M3) are predominantly granulocytic and differ according to the extent of maturation. M4 is both granulocytic and monocytic, where as M5 is predominantly monocytic, M6 shows primarily erythroid differentiation and M7 is acute megakaryocytic leukemia. (Wintrobe's Clinical pathology. 2nd volume, 1998)

Acute lymphocytic leukemia (ALL) is the most common cause of malignancy disease affecting children accounting for approximately $30 \%$ of childhood cancers. Although affecting all age groups ALL have its highest incidence children between the ages of 1-5 years, with a peak at 3-4years.A slightly male 
predominance $(57 \%)$ has been noted in all demographic analysis of the diseases. Based upon FAB classification ALL is distinguish in to three sub types(L1,L2,L3)based upon the morphology, cell size , nuclear shape , number and prominent of nuclei and relative amount and appearance of the cytoplasm

\section{STAINS}

\section{MATERIALS AND METHODS}

\section{Giemsa stain, Jenner Stain and MPO (Myeloperoxidase) were used}

The data were collected retrospectively. The clinical records of consecutive patients diagnosed to have acute promyelocytic leukemia between January 2002- 2008. A total of 26 cases formed the basis of the study. All relevant data including clinical record concerning age, sex, laboratory finding, cytochemistry, cytogenetic, Flow cytometery, haematological parameter and history of bleeding were retrieved from the laboratory records departments of the Laboratory. In all cases Bone marrow slides were examined and whenever necessary they were restained. Cytochemical stains such as Myeloperoxidase (MPO) were also used when necessary.

\section{RESULTS}

A total of 206 patients were diagnosed as acute leukemia. Out of which 94 cases were Acute Myeloid Leukemia (AML). Out of AML, 26 cases were conformed as Acute Promyelocytic Leukemia (APL).Thus the incidence of APL among total cases of acute leukemia was $12.6 \%$ and constituted $27.6 \%$ of total AML cases.

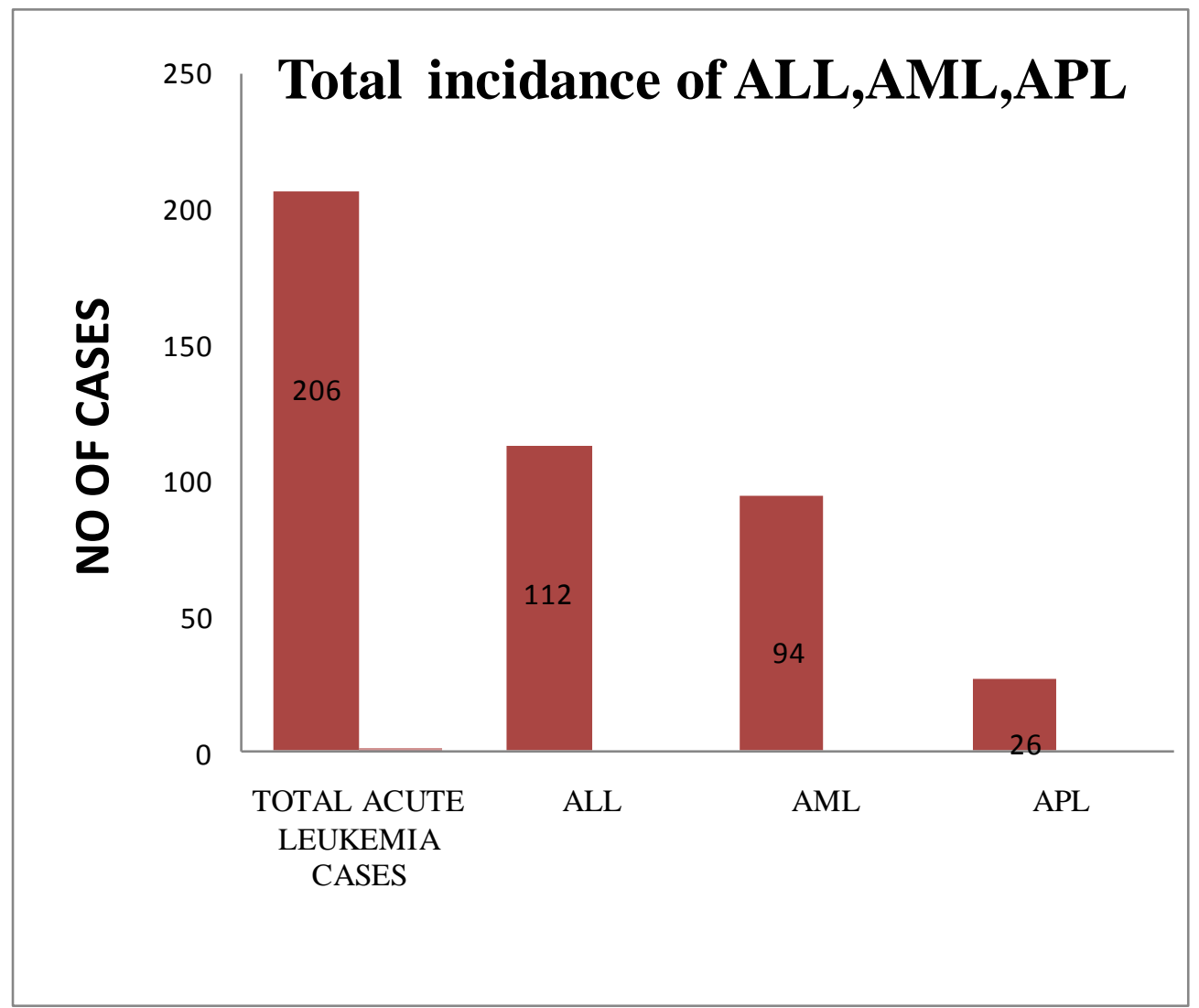

Fig 1: Incidence of ALL, AML, APL

\begin{tabular}{|lll|}
\hline Types of leukemia & No of cases & Percentage (\%) \\
\hline Acute lymphocytic leukemia ( ALL) & 112 & 54.3 \\
\hline Acute myeloid leukemia ( AML) & 94 & 45.6 \\
\hline Acute promyelocytic leukemia( APL) & 26 & 12.6 \\
\hline
\end{tabular}

Table 1: Incidence of ALL, AML, APL

Age Distribution of acute promyelocytic Leukemia (FAB-M3)

The age of the patient at the time of diagnosis varied from 16 to 71 years. The mean age of incidence was 40 years. The majority of the leukemia was between the age of 21-40 years. 


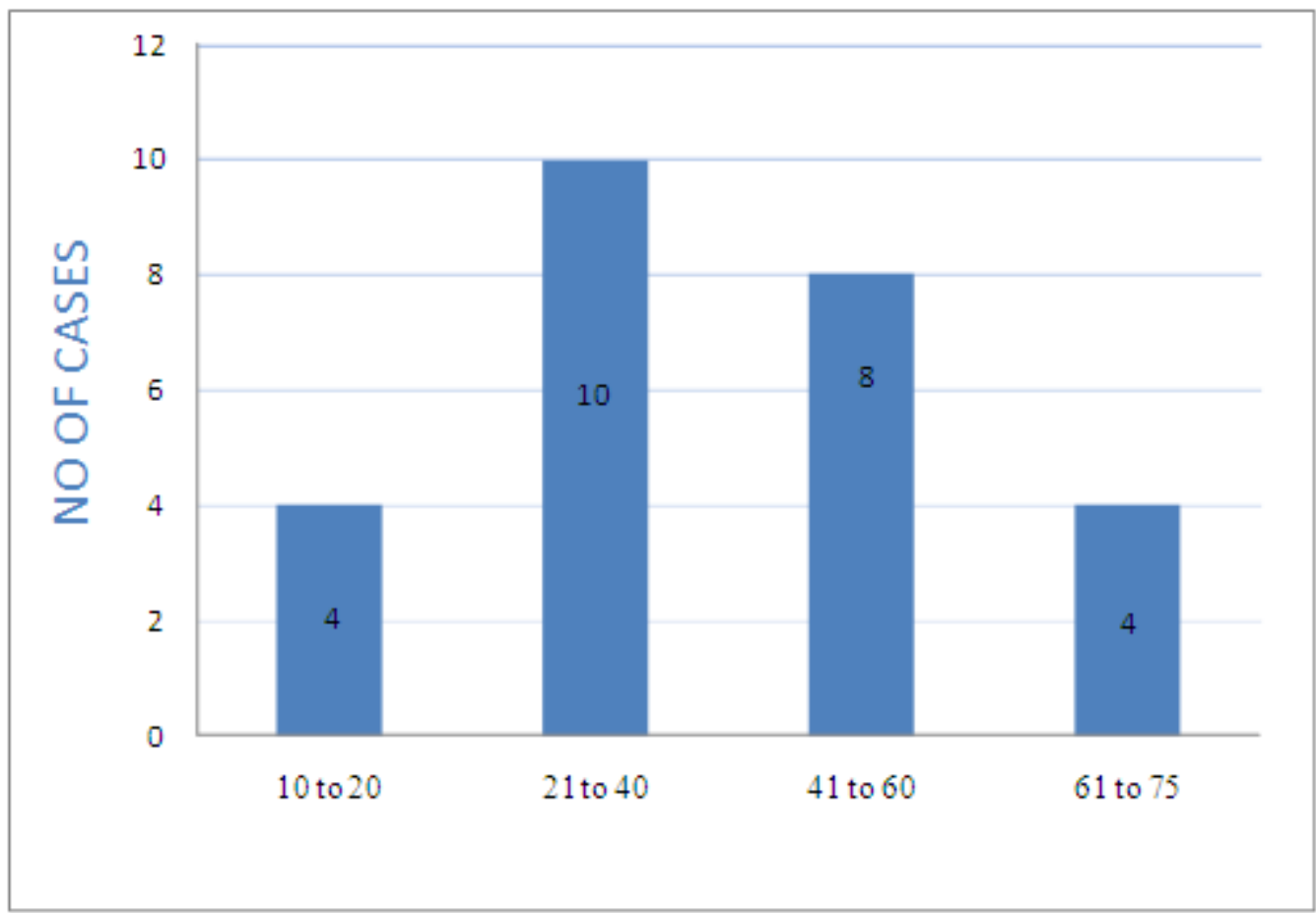

Fig 2. Age Distribution in APL Patients

\begin{tabular}{|lll|}
\hline Age in years & No of cases & Percentage (\%) \\
\hline $\mathbf{1 0 - 2 0}$ & 4 & 15.3 \\
\hline $\mathbf{2 1 - 4 0}$ & 10 & 38.4 \\
\hline $\mathbf{4 1 - 6 0}$ & 8 & 30.7 \\
\hline $\mathbf{6 1 - 7 4}$ & 4 & 15.3 \\
\hline
\end{tabular}

Table 2: AGE DISTRIBUTION IN APL PATIENTS

While analysing the data we found $38.4 \%$ of patients were in the age group of 21 to 40 years, $30.7 \%$ patients were in the age group of 41 to 60 years but no patient below 10 years was found.

\section{SEX DISTRIBUTION OF ACUTE PROMYELOCYTIC LEUKEMIA (FAB-M3)}

Out of 26 cases of Acute Promyelocytic Leukemia, 20 cases of male and 6 cases of female were found giving male to female ratio of 3.3:1

\begin{tabular}{|lll|}
\hline Gender & No of cases & Percentage (\%) \\
\hline Male & 20 & 77 \\
\hline Female & 6 & 23 \\
\hline
\end{tabular}

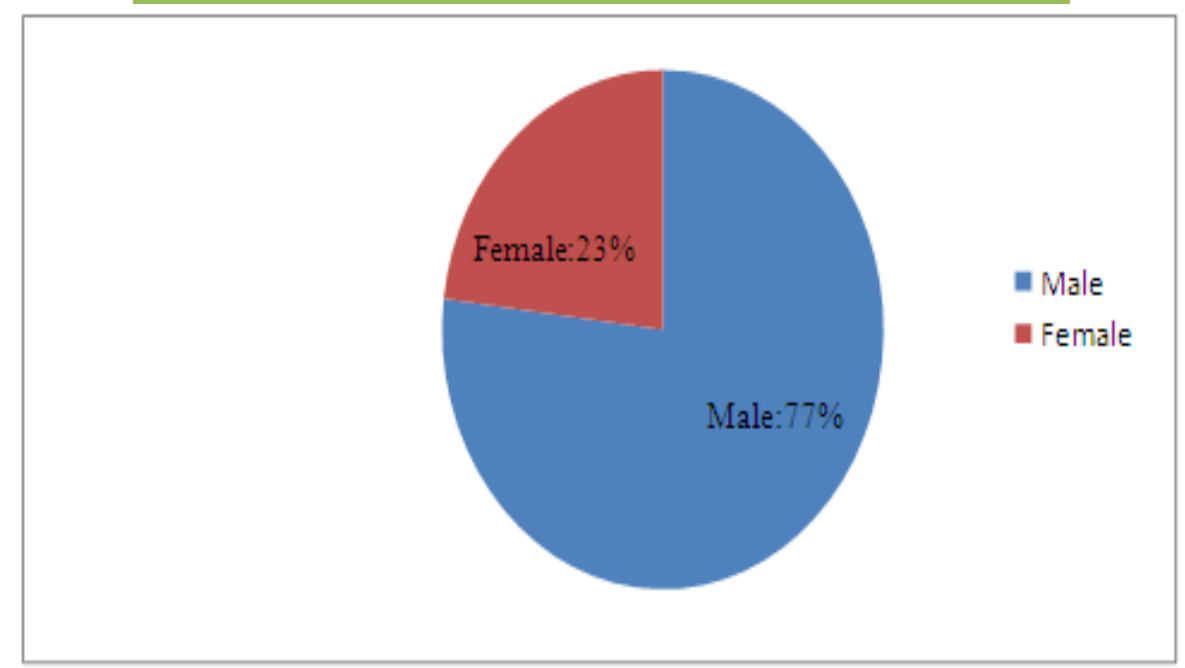

Table 3: Sex distribution of Acute Promyelocytic Leukemia (APL) Patients 
ABSOLUTE PLATELET COUNT IN APL (FAB-M3)

Absolute platelet count of the patient at the time of diagnosis varied from seven thousand (7000/cumm) to three lakh seventy two thousand (3.72lakh/cumm) with the mean platelet count of sixty thousand five hundred and seventy two cells $(60572 /$ cumm $)$

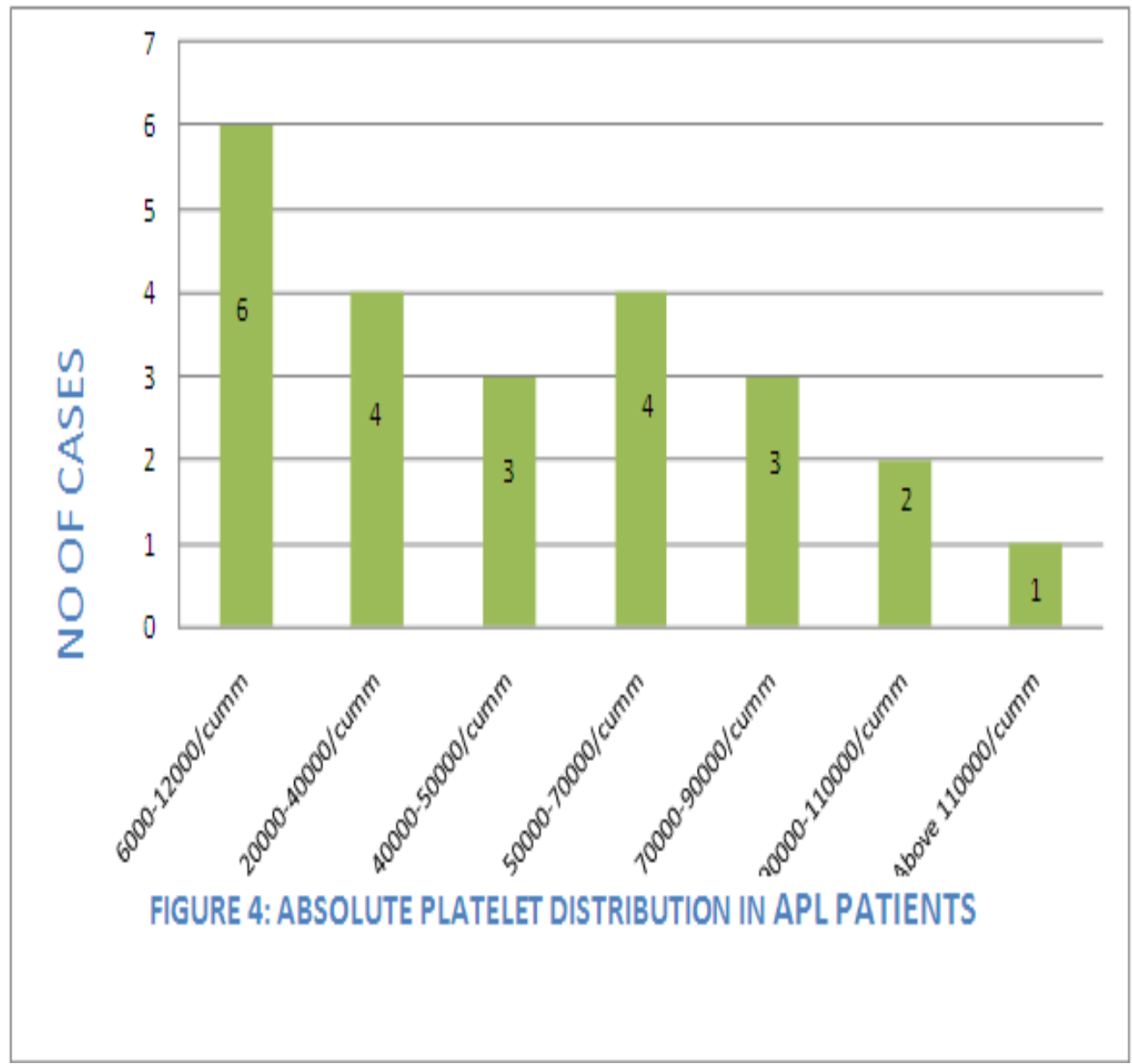

Fig 3: Sex distribution of Acute Promyelocytic Leukemia Patients

Figure 4: absolute platelet distribution in apl patients

\begin{tabular}{|c|c|c|}
\hline $\begin{array}{l}\text { Platelet count } \\
\text { /cumm }\end{array}$ & No of cases & Percentage (\%) \\
\hline $6000-20000$ & 6 & 23.0 \\
\hline $20000-40000$ & 4 & 15.3 \\
\hline 40000-50000 & 3 & 11.5 \\
\hline $50000-70000$ & 4 & 15.3 \\
\hline 70000-90000 & 3 & 11.5 \\
\hline $90000-110000$ & 2 & 7.6 \\
\hline Above 110000 & 1 & 3.8 \\
\hline
\end{tabular}

Table 4: Absolute platelet distribution in Acute

Promyelocytic Leukemia (APL) Patients

Majority of the patients were thrombocytopenic. 23\% patients have platelet count below 6000 to 20,000/cumm. The platelet count above $1.0 \mathrm{lakh} /$ cumm was found only in one patient. 


\section{HISTORY OF BLEEDING}

After studying the present and past history, the $70 \%$ of patients has either past or present history of bleeding. Most of the patients had history of gum bleeding. Few patients had history of black tarry stool and veginal bleeding.

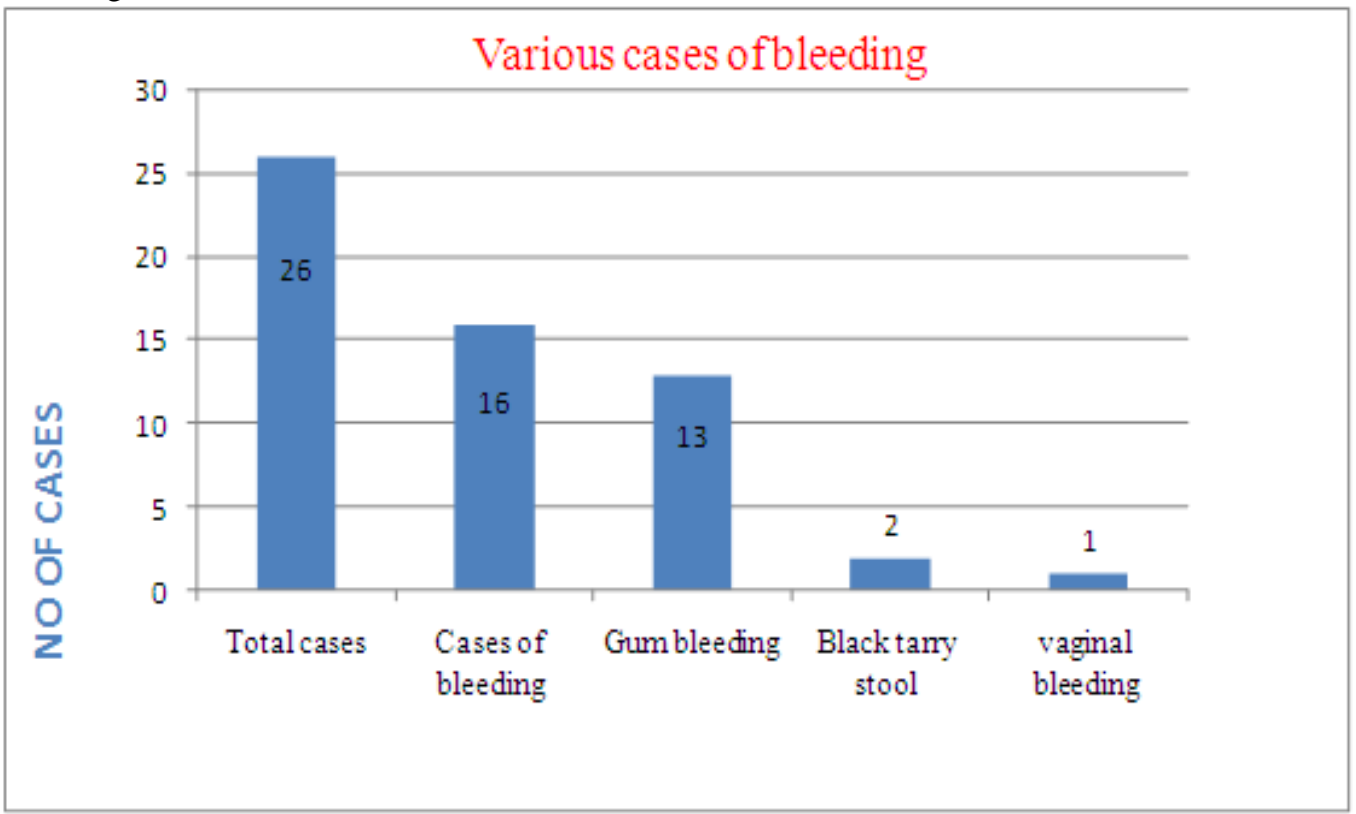

Figure 5: history of bleeding in APL patients

\begin{tabular}{|lll|}
\hline Total Cases (26) & No of cases & Percentage (\%) \\
\hline Cases of bleeding & 16 & 61.5 \\
\hline Gum bleeding & 13 & 50 \\
\hline Black tarry stool & 2 & 7.6 \\
\hline Vaginal bleeding & 1 & 3.8 \\
\hline
\end{tabular}

Table 5: history of bleeding in APL patients

In our study $61.5 \%$ patients had the present or past history of bleeding. Majority of the patients (50\%) had history of Gum bleeding. Few patients had history of vaginal bleeding and black tarry stool.

\section{HLA-DR FOUND IN APL PATIENTS}

While observing the data of the patients 19 out of 26 cases were analysed HLA-DR. Out of which 18 cases were negative HLA-DR and only 01 case was found equivocal.

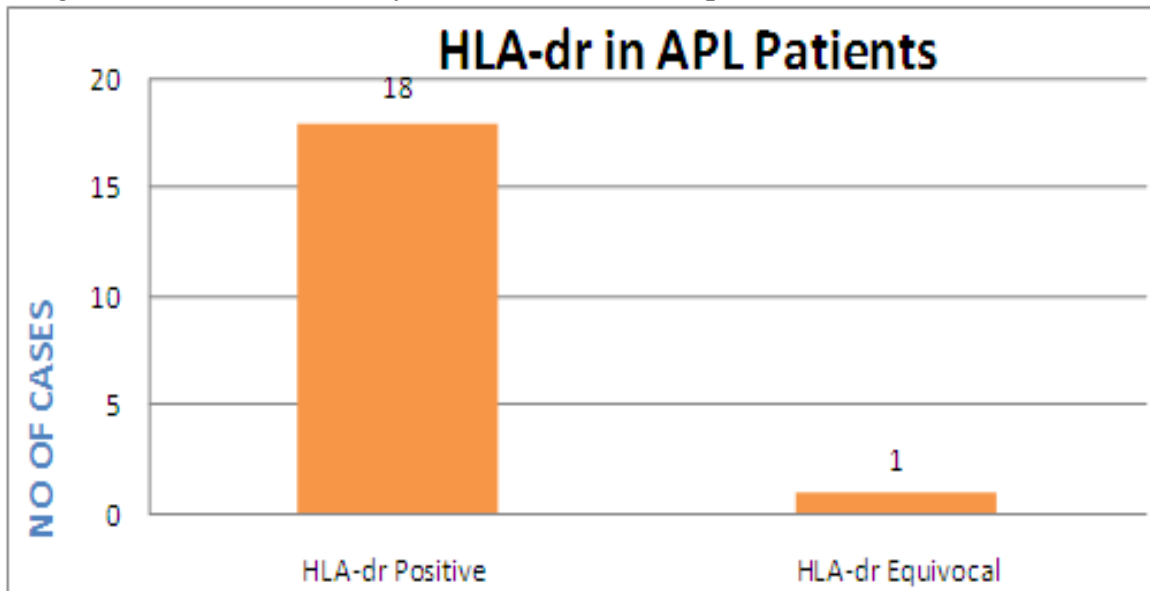

Figure 6 hla-dr in APL patients 


\begin{tabular}{|lll|}
\hline HLA-DR & No of cases & Percentage $(\%)$ \\
\hline Positive & 18 & 69.1 \\
\hline Negative & 01 & 3.8 \\
\hline
\end{tabular}

Table 6: hla-dr in APL patients

The HLA - dr cases were found in $69.1 \%$ (18) patients while only in one patient was found equivocal.

\section{PML-RARA FINDINGS}

While observing the PML-RARA, 19 cases were found positive while only 2 cases were found negative. The morphology of these patients suggests Acute Promyelocytic Leukemia.

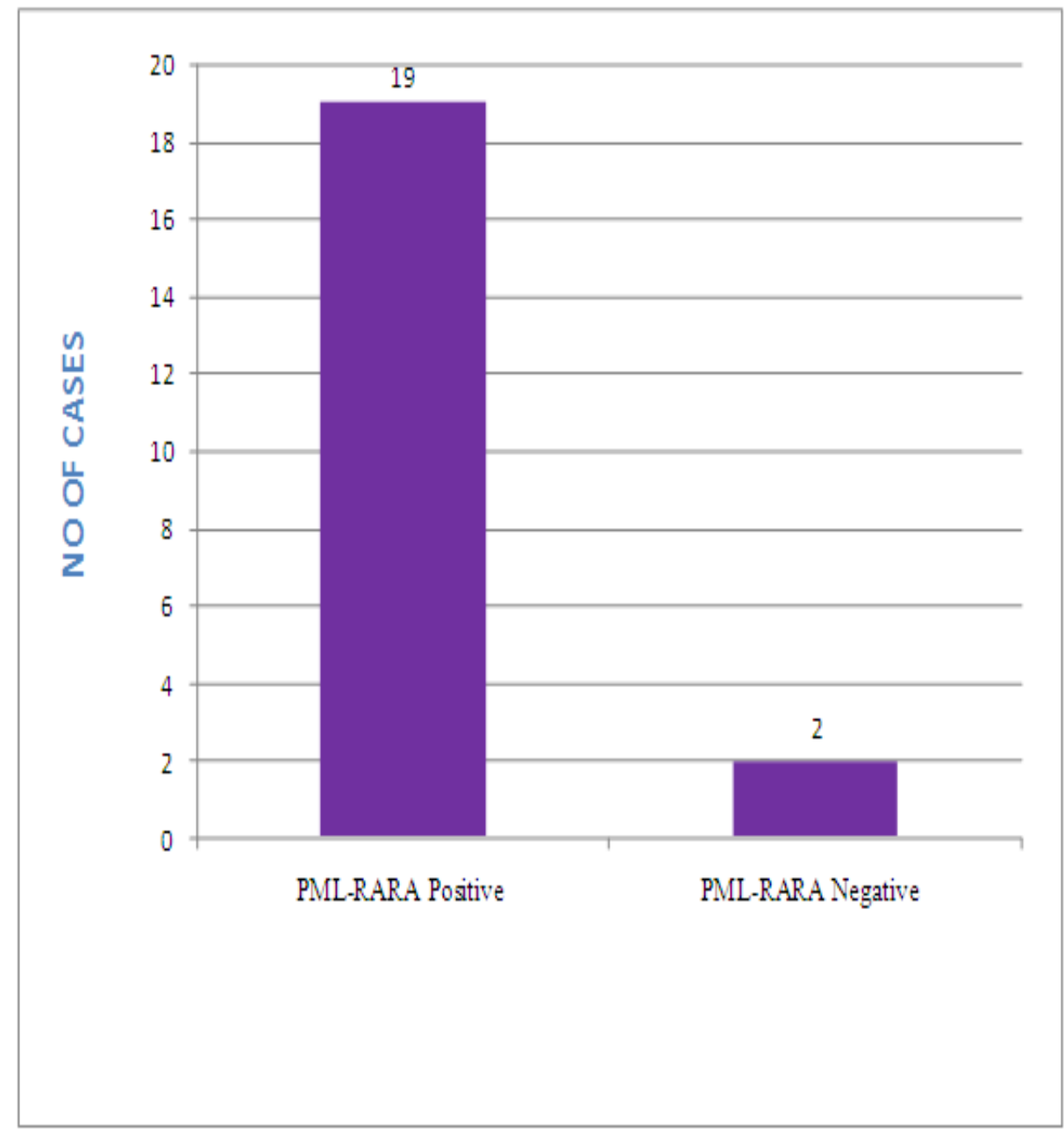

Figure 7: pml-rara findings in APL patients

\begin{tabular}{|lll|}
\hline PML-RARA & No of cases & Percentage $(\%)$ \\
\hline Positive & 19 & 73.0 \\
\hline Negative & 02 & 7.6 \\
\hline
\end{tabular}

Table7: pml-rara findings in APL patients

In our study $73.0 \%$ of the patients were PML-RARA Positive were as two cases Were found PML-RARA negative.

\section{BONE MARROW EXAMINATION}

Most of the bone marrow smears full filled the FAB criteria (i.e. $\geq 30.1$ myeloblast + promyelocyte with prominent granules). 19 cases in the study showed blast+ promyelocyte more than $30 \%$.In few cases predominant cells (almost 80\%) were promyelocyte having moderate to abundant cytoplasm with azurophilic granules. Auer rods were seen and myeloperoxidase (MPO) was ++ to +++ positive in various cases. Four cases of micro granular variant were also seen. 

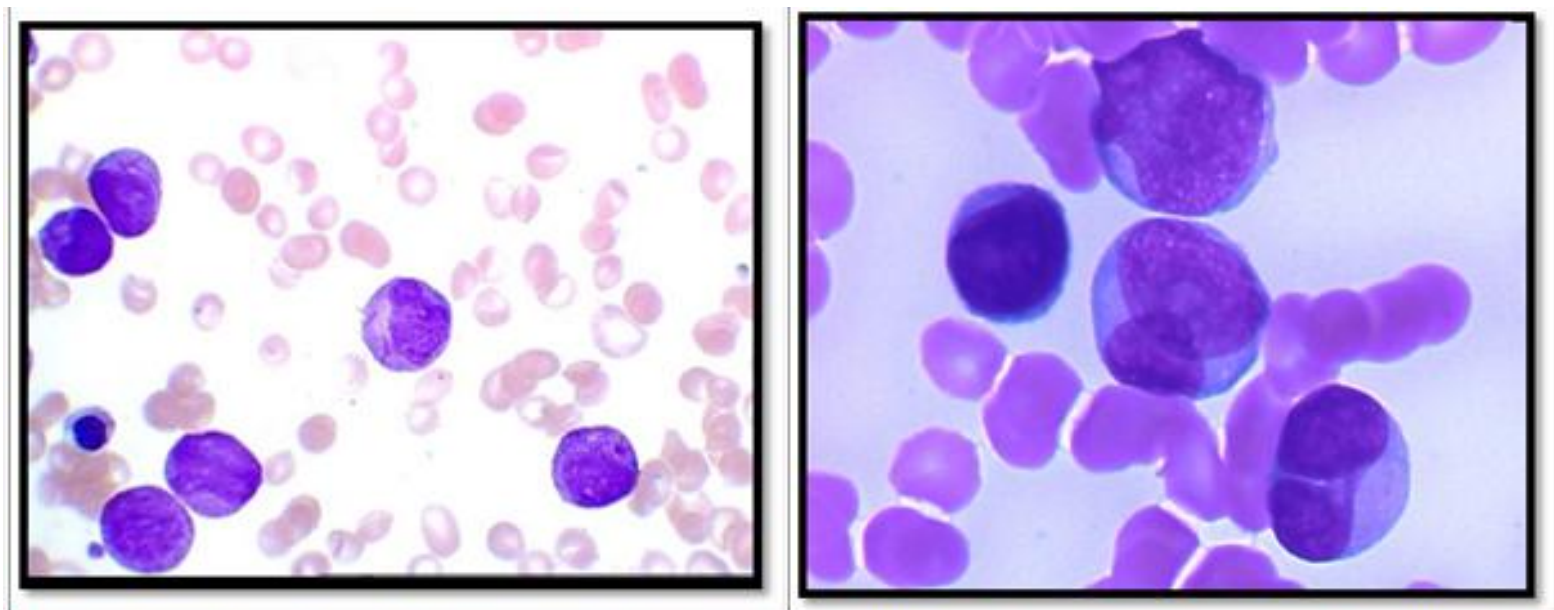

Morphological example of a hypergranular myeloblast Morphologic example of a hypogranular myeloblast in in APL. Note the azurophillic granules and Ayer rods. APL. Note the lack of granules and bilobed nucleus.

\section{FIG: 8}

\section{DISCUSSION}

The total of 20 cases formed the basis of the study and all the relevant data including clinical record concerning age, sex, laboratory findings, cytochemistry, cytogenetics, haematological parameter, flow cytometric and history of bleeding reports were retrieved from the laboratory records of the department. There are only few studies available in Indian literature on relative incidence of APL in Indian population. The data in literatures were analyses and compared with the observations of present study.

Douer D et al, 1993 was the first to call attention to the increased incidence of APL among patients of Latin Americans descent. Subsequently reported data from hospital based registries in Mexico, Peru and Spain also showed a relatively high incidence of APL .Similarly; Estey et al (2001) reported 120 cases of APL (9.6\%) among 1245 patients with newly diagnosed AML treated at the MD Anderson Cancer Center, Houston, and Taxes.

A high frequency (24\%) of APL was noted among AML cases at the Los Angeles County- University California (LAC-USC) medical center. In comparison with the expected frequency of $5 \%$ to $15 \%$.APL, a relatively rare haematological malignancy is highly curable with current treatment strategies. However these strategies may be unavailable in countries with fewer resources available. A review of records in several Latin American countries revealed that approximately $30 \%$ of deaths among children and adults with APL were caused by early complications associates the disease or its treatment. Furthermore, APL accounts $20 \%$ to $25 \%$ of AML in these countries.

According to the study the mean age of incidence was found around 21 to 40 years (38.4\%) and few patients were found above 60 years of age. Two patients in adolescence and none in children below 10 years were seen. The finding of our study is comparable to other international study where they found the median age of patients between 15 to 44 years. Brunning RD et al, 1990 and Italian Paediatric haematology and oncology group $2000(80 \%)$ of cases.

In our study the sex incidence of APL was found higher in males as compared to females with a ratio of 3.3:1.The most of the patients were thrombocytopenic with platelet count less than 40000/cumm was seen in $43 \%$ cases while only one patient has platelet count above 1.0 lakh/cumm (fig 4 and table 4 ).Most of the patients with low platelet count has history bleeding (70\% cases) most of them had Gum bleeding (50\%). The study is quite similar conducted by Avvisati G. et al 2001 \& Dally N et al,2005.According to their study $80 \%$ to $90 \%$ had a several hemorrhagic syndrome wit low platelet count.

In our study 19 cases were analysed for HLA-DR expression, out of them 18 cases did not show any expression whereas only one case showed equivocal expression (Fig $6 \&$ table 6). The study was quite similar with the study conducted by Jclin oncol et al, 1992 and Wetzler M et al, 2003 where they found that both of the variants (i.e. hype and hypo granular variant) were absent for HLA-DR

The confirmatory test for the diagnosis of Acute promyelocytic Leukemia is the molecular study of PML-RAR $\alpha$ i.e. $t(15: 17)$.After analysing the data 19 cases were found PML-RAR $\alpha$ positive while two cases were found PML-RAR $\alpha$ negative and also HLA-DR negative and the morphology suggest Acute promyelocytic leukemia (Fig $7 \&$ table 7). The result of our study is similar as the study conducted by Melo RA, et al 2006 and Gustavo J et al, 2002, where they found PML-RARA positive in $98 \%$ cases.

There are some other cytogenetic variants of Acute promyelocytic Leukemia which include t (11:17) (q23:q11) (51) and with $t$ (5:17) involving a fusion of the PLZF gene on 11 q23 with RAR $\alpha$ on 17q11 (51) and 
with $t(5: 7)$, nucleophosmin/RAR $\alpha$ (NPM/RAR $\alpha$ ) fusion (52) both of which associated with resistance to ATRA and have a worse prognosis than $t$ (15:17). In present study two cases were found PML-RAR $\alpha$ negative $\&$ also HLA-DR negative. So possibility of existence of other cytogenetic variation of APL might be present which should not be ruled out.

\section{CONCLUSION}

There are Very few studies available in Indian literature on the relative incidence of APL in Indian population, the data in literatures were analyzed and compared with observation of present study. The result of the study was compared with the observations of other study available on the subject and after comparative review of available literature the following conclusion was drawn:

The incidence of APL (26\%) was found to be higher at our centre of study in comparison to other studies. So there is a need for multicentric studies having a large population based to know actual incidence rate in our country. Also the environmental and occupational factors with incidence of APL are needed. The population bases epidemiological study is required to validate the findings.

Males were found to be affected more comprising $76.9 \%$ of the cases giving a male and female ratio (M: F) of 3.3:1

The main age incidence of APL in our study was 40 years. The majority of the patient was the age group between 20 to 40 years but few patients were found above 60 years of age. We record only one patient in adolescence and none in children and the finding were similar to the study of Brunning PD et al.(1990) and Italian pediatric haematology and oncology group 2000(in 80\%) of cases.

As the literature on the subject of hemorrhagic manifestation on APL status that up to $90 \%$ of patients Avvisati G.et al and Dally N.et al 2005. They present hemorrhagic manifestation secondary to DIC and it is a characteristic feature of APL. The incidence of hemorrhagic manifestation in our study was found to be $70 \%$ the association of thrombocytopenia with well illustrated in literature and Avvisati G et all 2001 and Dally $\mathrm{N}$ et al 2005 also found less than 10,000 and 30,000/cumm respectively in their studies. Thrombocytopenia with median count of less than 40,000 was found in about $43 \%$ cases which were in close relation Avvisati G et al 2001 and Dally n, et al 2005.

The equivocal expressions of HLA-DR were found in only case and the rest of the cases were HLA-Dr negative. The expression of HLA class II antigen on acute myeloid blast is available and the biological significance of HLA-Dr is not clearly known. And J clin oncol et al, 1992 and Wetzler M et al, 2003 sought to characterize the case of AML which are HLA-DR negative and concluded that HLA-Dr negative includes approximately equal no. Of cases of APL and they states that diagnosis of APL along with morphological HLADR antigen expression is required along with cytogenetic and molecular confirmation. This of our study was an agreement with the majority of the patients.

The findings of PML-RARA were similar to the study done by Melo RA et al 2006 where he found the hybrid gene PML-RAR $\alpha$ present in $98 \%$ of cases, encodes a fusion protein essential to the pathogenesis of the disease of APL. In our study after analyzing the data of 21 cases 19 cases were found PML-RARA positive (i.e. $73 \%)$.

\section{REFERENCES}

[1]. R.M Stone and R.J Mayaer, The unique aspects of acute promyelocytic leukemia. J Clin Oncol., 1990 Nov;8(11):1913-21.

[2]. Hernandez JA, Land KJ, Mc Kenna RW. Leukemias, myeloma and other lymphoreticular neoplasms. Cancer 1995; 75:381-94.

[3]. $\quad \underline{N \text { Asou, }} \underline{\mathrm{K} \text { Adachi }}, \underline{\mathrm{J} \text { Tamura }}$ A Kanamaru, S Kageyama, A Hiraoka, 'et al”.Analysis of prognostic factors in newly diagnosed acute promyelocytic leukemia treated with all-trans retinoic acid and chemotherapy. J Clin Oncol 1998, 16:78-85.

[4]. Avvisati G, Lo Coco F, Mandelli F.Acute promyelocytic leukemia: clinical and morphologic features and prognostic factors. Semin Hematol. 2001; 38:4-12.

[5]. $\quad$ Chen Z, Chen GQ, Shen ZX, Chen SJ, Wang ZY. Treatment of acute promyelocytic leukemia with arsenic compounds: in vitro and in vivo studies. Semin Hematol. $2001 \mathrm{Jan} ; 38(1): 26-36$.

[6]. Wetzler M, McElwain BK, Stewart CC, Blumenson L, Mortazavi A, Ford LA, et al.HLA-DR antigen-negative acute myeloid leukemia. Leukemia. 2003;17:707-715.

[7]. Dally N, Hoffman R,Haddad N, Sarig G, Rowe JM, Brenner B. Predictive factors of bleeding and thrombosis during induction therapy in APL-a single experience in 34 patients. Thromb Res 2005; 116:109-14.

[8]. Melo RA, de Vasconcellos JF, Melo FC, Machado CG, Lacerda TM, Souto FR. PML- RARalpha fusiogene transcripts and biological feature in acute promyelocytic leukemia patients. Clin Lab Haematol. 2006 Apr; 28(2):126-9.

[9]. A text book of haematology Mckenzie S.B.2nd edition 1995.

[10]. A text book of 'Wintrobe's clinical pathology" 2nd volume, 1998. 